\title{
Personalization by means of Visual Representations of Workshop Spaces in Cyprus Turkish Community
}

\author{
Senih Çavuşoğlu, Eastern Mediterranean University, North Cyprus Zehra \\ Öngül, Eastern Mediterranean University, North Cyprus \\ Banu Tevfikler Çavuşoğlu, Eastern Mediterranean University, North Cyprus
}

\begin{abstract}
Space is a living entity in regards to life, speaking loud about its inhabitants. In this study, individual features of occupants as an effective factor in the generation of space is addressed. Interpreting individualization of space through values like identity, culture, lifestyle of the inhabitants is aimed.
\end{abstract}

In this sense, samples from workshops that once used to have an important place in the cultural fabric of Cyprus community, but now are almost extinct, have been chosen. Thus, spatial values by way of workshop types for varying works have been set forth to realize a space-character analysis towards the concept of individualization of space.

It is aimed to reveal the 'flavors' of space belonging to life, derived from workshop samples that show existence as a true character by the fact that they exactly overlap with the occupants' socio-psychological state and come to life as a living entity in parallel to the motion of the business. Evaluations have been accomplished via visual representations from photographs as the closest ways of sensing the space.

Keywords: personalization, visual representations, Cyprus Turkish community 


\section{Introduction}

Space, which meets the vital needs of human beings, contains the most important clues about the life of the individual, of humans, the smallest building block of society. Accordingly, every space that is created tells a lot about its inhabitant. As the spaces evolve and shape with the inhabitant's liking, character and life-perspective actually come to life as a reflection of it. With this understanding, in this study, the inputs that are the factors in the formation of space will be discussed and their importance will be mentioned, and the most important factor in the formation of space, the inhabiting human will be addressed. The aim of this study is to construe the topic in the context of personalization of space, by going through the values such as the occupant's culture, life style.

Presentation of the 'tastes' of life of space through the workshop samples, which appear to be randomly arranged from the outside, but directly overlap with the socio-psychological state of its inhabitants, as well as emerging in a form suitable for the mobility of the business, existing as if it is a character, and selected based on these considerations, constitutes the main aim of the study. The evaluations will be done by interpreting through photograph that feels the space closest to the reality.

In this sense, different examples of workshop spaces that have held an important place in Turkish Cypriot culture until recently, but are now decreasing in number or disappearing, have been chosen. Thus, spatial values through various types of workshops for different works have been tried to be revealed in the context of human-space relation; a spacecharacter interpretation has been conducted with regards to the concept of personalization of space.

\section{Space as an Identity}

The founding elements of space are time and motion, together with solid, void, texture, light, color, and shadow associations. Space can only be felt, sensed, and perceived by these features. In terms of humans' formation of the self, space is a fundamental category. Time and space are the basic grounds of human actions. For this reason, every discussion, every research about human beings must take into account the categories of time and space. The journey of 'being' in time, the reckoning that the human engages with time, and positioning self over time is important for making interpretations about life. In respect to the relationship between human 
and space, human's creating spaces for the self, and naming the self through his/her space also has the same importance.

Many different disciplines and arts have identified space as their main focus of study. Space has been dealt with at the intersection of art and science as a fundamental category that allows interpretations with a wide range of expansions. Space is a very important concept because it is a phenomenon on its own, and at the same time, due to its relationship with human beings, and for this reason, it is an area of great interest.

Space possesses an image characteristic that reveals the person. With this aspect, space can be associated with the concept of identity. In space, human beings see themselves, construct themselves. Space is an accumulation point of life, one of the most important indicators of human existence. Human beings announce their own existence through their 'space'. In this sense, space stands out as an element of identity; it is related to the main factors that make up human identity such as memory, belonging, character, tendency, social relations, status, etc. In this sense, space carries hints about the person's identity by pointing directly at the person. The degree and quality of acquiring space, using space, and approaching space can be a reference for people and society. In this respect, the answer to the question of 'what kind of person' finds a response in the context of space.

Although 'space' is often understood as merely the places that came out of an architect's pen, space is, in the most general term, all of nature. It is environment, geography, place, and in abstract sense it is extent. Although it is commonly used for 'living space', it also includes the meanings of surroundings, environment, world, universe' (Alver, Köksal, Int1). It is necessary for the continuation of life. It is the avenues, streets, mountains and plains. It is the rooms, houses, offices, hotels, schools, mosques, hospitals, patisseries, jails, and workshops.

Most of the places where people live may not be objects of architectural design. An architectural value may not be mentioned for all of the places where human life takes place, because people actually live everywhere. Whether the space is designed or not; whether it is successful or not according to a set of design principles. For example, while waiting on a bus stop, people live... In a workshop people live. 


\section{The Effect of Culture and Life Style on Space}

Culture is formed in relation to environment-human, human-human, human-object and objectobject relationships. All these relationships form a complex network in itself. This network that creates the environment is realized by the organization of four basic elements. These are space, meaning, communication, and time (Rapoport, Amos). Rapoport defines culture as "a conceptual and shortcut summary put forward for the special coincidences of the great diversity of the human phenomenon, a proposed explanation" (Rapoport, pp.103-104). Based on this, Rapoport argues that culture, which is not seen, is abstract and in fact a norm, creates "lifestyle", which is formed and shaped by world views of people, their values, ideals, expectations and standards, and becomes personalized. Lifestyle, which emerges as action systems of individuals and continues to shape with different inputs as we live, comes out in space as a reflection of the character of the person.

Culture is the collection of intellectual adoptions of people -no matter which geography they are in-, such as the kind of lifestyle, purpose of existence in the ongoing life, and action pattern, although they demonstrate certain difference. "Culture is the entire reality that people exist within and has revealed. Changing and transforming nature in ways that are suitable to human beings, is a process and efficiency of humanization" (Uygur, 2003). Based on this narrative, it would not be wrong to say that everything that develops is shaped, and formed around human being is a part of his/her culture. "Ownership of culture makes us all human and defines our characteristics; but, on the other hand it separates us from each other in terms of our language, our religion, our eating habits, our rules and many other components of culture in such a way that we can even talk about "fake-species". Many important characteristics of people depend on culture" (Rapoport, pp.45).

Here at this point, culture, which emerges around human beings as a subject among many different inputs, is being defined by Marx as everything created by human beings in response to nature's creations (Güvenç, 1996). Undoubtedly, one of the most important of these creations is a new entity, which will primarily separate human beings from the external environment and atmosphere so that they can continue their lives, an entity in which there is a new atmosphere with its own boundaries, specific to itself. This new entity with defined "boundaries" is actually called the "space" created by the designer. Space, which consists, in general, of a combination 
of vertical and horizontal planes with the use of many different materials, comes to life by being arranged in line with different purposes of a single individual or multiple individuals. Space or spaces that are shaped by a combination of one or more functions depending on the needs they need to accomplish are one of the most important main factors that enable human beings to live like human beings since ancient times. For this purpose, architecture that puts boundaries to space so that we can live in it, and creates the order that surrounds our lives, is a very special functional art (Rasmussen, pp.12). The forms and spaces that architecture generates, creates, and defines for the people are created not only to be looked from the outside, but much more importantly, to be lived in, to be used, and to be worn out. The environment and spaces created by the architect, or other designers involved in the design of space, for the inhabitant, i.e. the actors, is actually a game, in other words, a kind of stage, which consists of inanimate, soulless planes without character before coming into use. The unused, untouched, and 'uninhabited' structure becomes different from its intended purpose; in fact it becomes meaningless and loses its value. In other words, space cannot exist without humans.

"No other art is so closely related to the daily life of a person, from cradle to grave" says Rasmussen, and points out the strong relationship between architecture and the inhabitant. (Rasmussen, pp.16) Existing at every moment of life, architecture is in a one-to-one relationship with its inhabitants through the many different functions it provides. One of the most important purposes of architecture is to create spaces for humans. Spaces that are shaped by many different inputs are also arranged by inhabitants according to the function they serve, and this is very significant. In fact, spaces come to life by being shaped by our past, our likes, our memories, things we share, sometimes things we do not share, our consciousness without us noticing, photographs, books, furniture, paintings, drawings, and clothes of our understanding, and many more different 'values' which essentially belong to the person. Accordingly, spaces are a mirror, a reflection of their inhabitants. From this point of view, "space surrounds every aspect of human experience with all its dimensions" (Duyan, Efe Int2).

Spaces intended for different cultures, tastes, truths, fields of expertise, etc. for different inhabitants, gain a character with the 'person' and differentiate from each other. Space and environment begin to be lived in only when integrated with the inhabitant, they revive with the presence of its touches, they find life and acquire a soul; that is to say they are involved in life. 
From this moment on, it can be started to talk about personalization of the spaces that gain a character, obtain an identity by the inhabitant. With this understanding, as spaces are used, they are shaped according to the needs of the inhabitant, its way of life, culture, point of view towards life, and character, and they contain many values in them about life. In this sense, spaces can also be treated as a life story of the inhabitant that has not been previously conceived or written, their past, and their dreams and fantasies for the future.

In this sense, even though their numbers have significantly declined today, the "workshop spaces' that have found their rightful place in the public array in terms of social, political and economic aspects of the Turkish Cypriot culture, is a type of space that is worthy of consideration or examination. Within the scope of this study, recording examples from these spaces, which are personalized via inputs by their inhabitants, are examined via visual representation. This is a step towards creating an archive in a cultural sense. In this sense, Foucault gives the name archive to the "game of rules that determine the emergence and disappearance of expressions, the continuity of events and things, and their paradoxical existence within a culture" (Foucault, pp.9).

Time is a feature that balances one's values and communication with its surroundings in all dimensions; and is a constituent element in the cultural structure of society. In this sense, society, in the context of time, integrates the essence of culture with individuals. The real behavior of the individual can be understood in culture, which is the system that surrounds it. Culture can be described as the existence of common values and thoughts of people with common mutuality, and the transfer of these over time to individuals who constitute the people with common mutuality. In this context, culture can be regarded as a characteristic view of life and a way of shaping the environment. People with common mutuality having common standards of judgment, life styles, and activities, are also the fundamental reason in shaping their environments (Rapoport, 1980).

\section{Workspaces in the Turkish Cypriot Community - Workshops}

A human being is an organism moving towards a goal. It defines, interprets, and explores its physical surroundings, and is generally mobile and active (Proshansky, H.M., Ittelson, W. H., 
Rivlin, L.G.). The society and the physical environment in which human beings live in must allow them to be able to make choices as well as meeting their needs. Although a person as an individual lives in society and therefore needs to communicate, the needs of privacy inherent in a person differ according to the person's culture, social relations or the condition of the physical environment (Altman, Irwin). Just like workshop spaces that are stories of life that have not been pre-conceived and designed, thought or written by their inhabitant.

Over time, the space in which the person lives, and the images and the scenery inherited within, become the symbolic extension of the person him/herself. The person unconsciously identifies him/herself with the space, and in this context "begins to protect the space where s/he lives as a private property of his own" (Kalyoncu, Gülşah, pp.3).

Certain occupational groups that are less preferred today depending on various influences such as changing living conditions, needs, likings, manual labor being replaced by mechanization, and the fact that the material value of handicrafts is more than the machine product, actually belong to our past, to our culture or to 'us'. Functionality and operability of these occupational groups throughout the course of history has allowed these spaces to become beaten tracks; for example, Coşkun Usta's place, his workshop that originally serves as a tire dealer has become a gathering point, providing the social environment expected from a coffee shop (Photograph 1). In this sense, they are part of the social life within the society in a concrete manner with their spatial values.

Such workshop spaces are places where the inhabitant, in fact, shares him/herself without any limitations in cases where s/he may not do so in a family environment. The surfaces formed by pieces such as a calendar hanged on the wall, the poster of the team to which the inhabitant is passionately bound, the photograph of the inhabitant's favorite artist, etc., forms the texture in the space. As seen from the photographs, it is noteworthy to see a milestone ancestral figure that could not find a place at home for perhaps it did not fit the decor, finds its place here.

Suggesting that the successful - unsuccessful distinctions between the designed - nondesigned spaces should be "delved into", Duyan emphasizes that "every space in which the person breathes has value" and "it deserves the same amount of design interest" (Duyan, Efe, Int2). 
Based on the fact that the main purpose of this study is to implicate the spaces that are left out of the discussion from a design point of view in, it can be said that the values of the discussed workshop spaces are of a great importance.

\section{Visual Representation of the Selected Workshops in Terms of Personalization of Space}

Personalization, within the contexts of space, is a change that the inhabitant of the space intentionally makes to reflect his identity. Personalization involves marking the space or place, adding objects to it, and laying claim to objects and spaces. People use personalization of space to distinguish themselves from others (Twigger, Claire and Uzell, D.). Sometimes this happens consciously, and in most times unconsciously; and this is due to the need to control the area in which the person lives, the fact that it is an expression of its own aesthetic taste, and the desire to overlap one's own activity pattern with the living space (Wells, 2000). In this sense, personalization of a space is an expression of a person's emotions and personality throughout his/her space.

Personalization increases the attachment of the person to the space being lived in (Wells, 2000). In parallel with this, Altman, in a detailed description of domain of sovereignty, says that it is a mechanism in which an 'I-others' boundary is placed, and reveals that personalization is the communication of the individual or the group in a sense (Altman). When looked from this point of view, workshop spaces are the ultimate domains of sovereignty of the inhabitant. In the domains of sovereignty, one feels safe and takes the feeling that such areas provide spaces where the person can make decisions freely as s/he wishes and the person is in control.

Personalization of the space can be thought of as a form of sovereignty behavior in which the person marks and protects his or her own space with personal effects, and thus regulating his or her own social relations. In a sense, this is the expression of one's emotions and personality in an overlapping manner. This means that the person gains dominance in protecting that area and having control over that area, which further means that the person has control over space as much as over himself or herself. From this point of view, personalization of workshop spaces also creates the image that the work done at that workshop is done with skill and craftsmanship. 
From various methodologies that can be used in terms of visual representations, photographs of the workshops are used to represent the moments of the real life in there. In other words, the photographs are means to analyze the 'real life'. The spaces that house workshop professions are, in addition to the elements required by the function they primarily serve, values that are formed within the process through years of accumulation without being designed or planned, and especially by being randomly organized by their inhabitants. These places are striking examples of individualization of space. It is a very special place that belongs to the inhabitant, where the inhabitant expresses his/her likings, point of view towards life, joy of living, sadness, and relationships of friendship without being aware, without wanting to, in other words, unintentionally or subconsciously (Photographs 1,2). In this sense, Wells defines personalization simply as "making spaces more livable by people" (Wells, pp. 241).

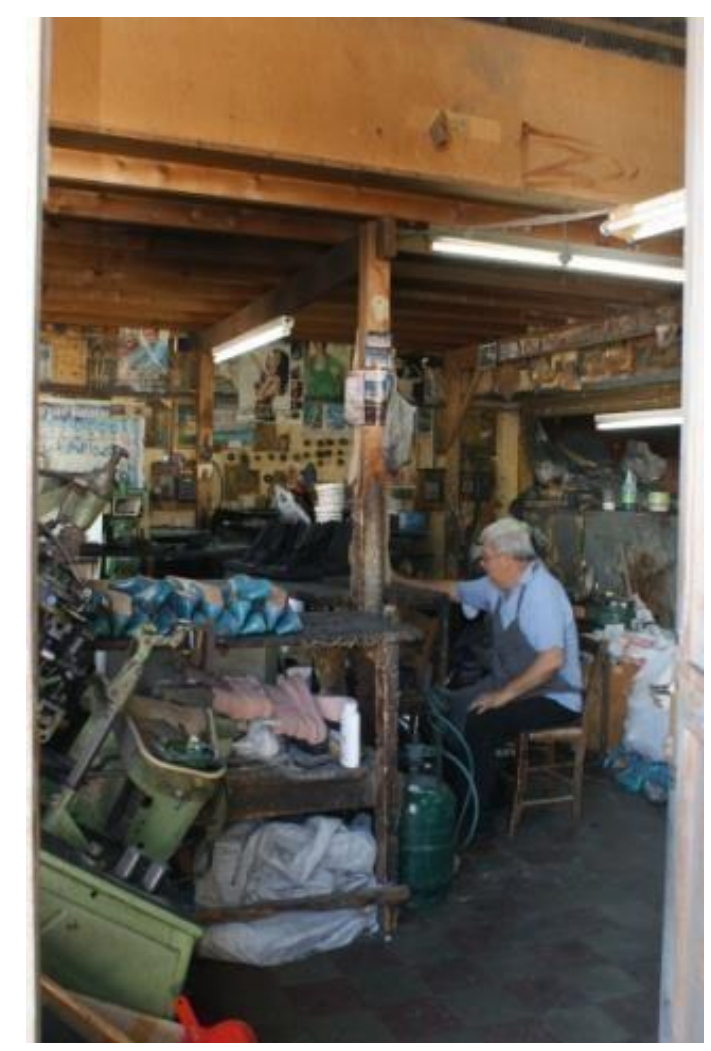

Photograph 1 Shoe Workshop, Senih Çavuşoğlu 


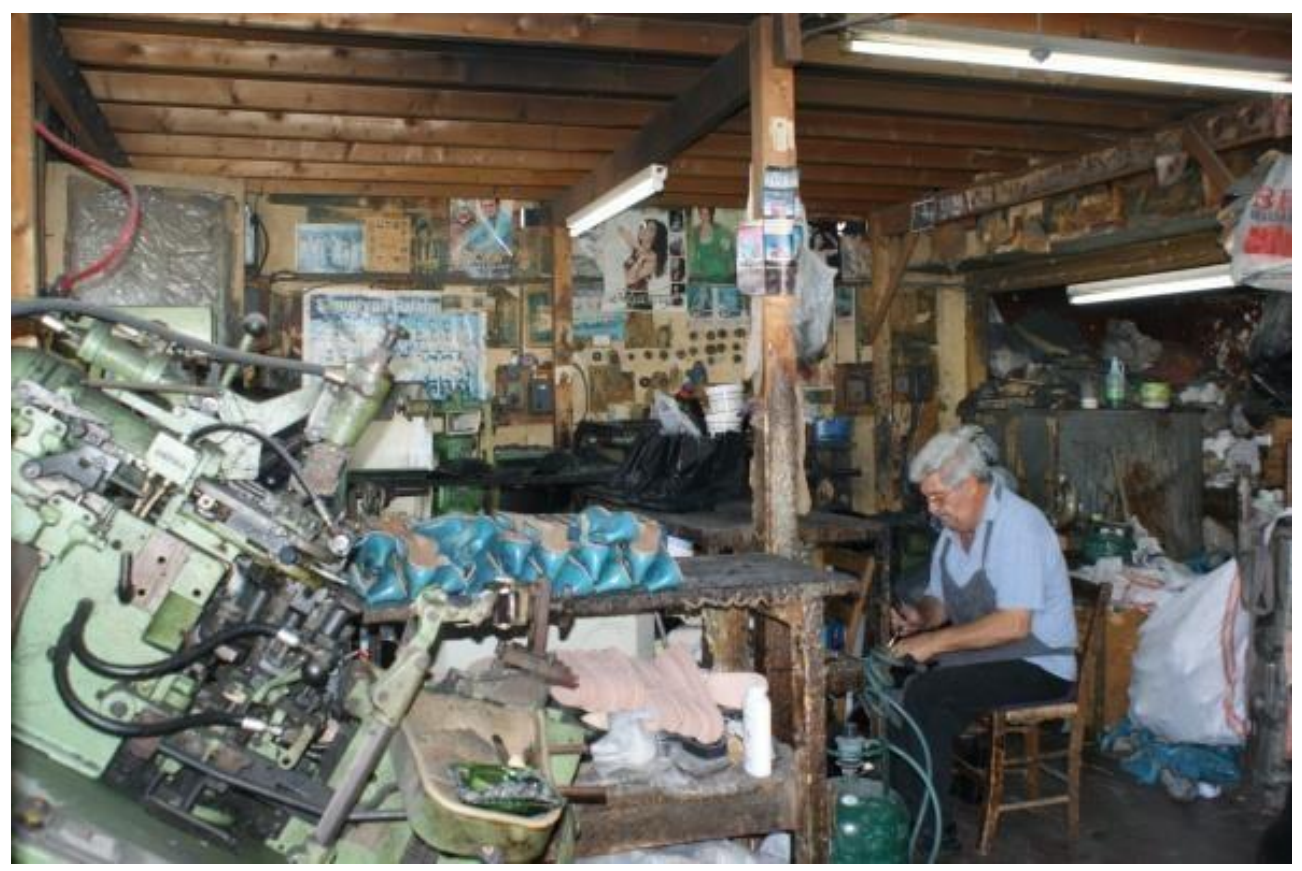

Photograph 2 Shoe Workshop, Senih Çavuşoğlu

Workshop spaces are production-based spaces as well as social gathering places. Therefore, efficient production of the work and having other people in the space who are not among the workers is made possible by the creation of domains of sovereignty in these spaces. Altman suggests that domain of sovereignty behavior is a mechanism in which an I-others boundary is placed, and reveals that personalization is in a sense the communication of the individual or group (Altman, 1975). When considered in the context of personalization of space, the master has the opportunity to skillfully do his work and to express that the workshop space is always open to others.

Workshop spaces, which create a strong connection between the past and the present as a space, as well as through the work that has been passed on from father to child, or performed, based on a master apprentice relationship, are a part of life, from different angles, related to the function of their service areas. Despite the fact that they are molded with change and transformation over the course of their service, these spaces, which are shaped and formed by the values and touches of the owners, especially as the inhabitants of the space, are actually the most private areas of the owners of the space, who are the master craftsmen in this case. A photograph, a calendar, a radio that has not been moved in years, a rosary, a poster, a team, or any other important detail most sincerely shared with the customers, or in a sense with friends, or with people that s/he shares the space with, is enough to make this space where the master 
productively spends most of his day as s/he likes it to be, and allows him/her to convey parts of himself, his spirit, character, and personality (Photographs 3,4,5). Thus, workshop spaces are places where individuals who make up the society stop by to get services in their own crosssections of life, where they actually find something out of their own past, or 'their own', without knowing it.

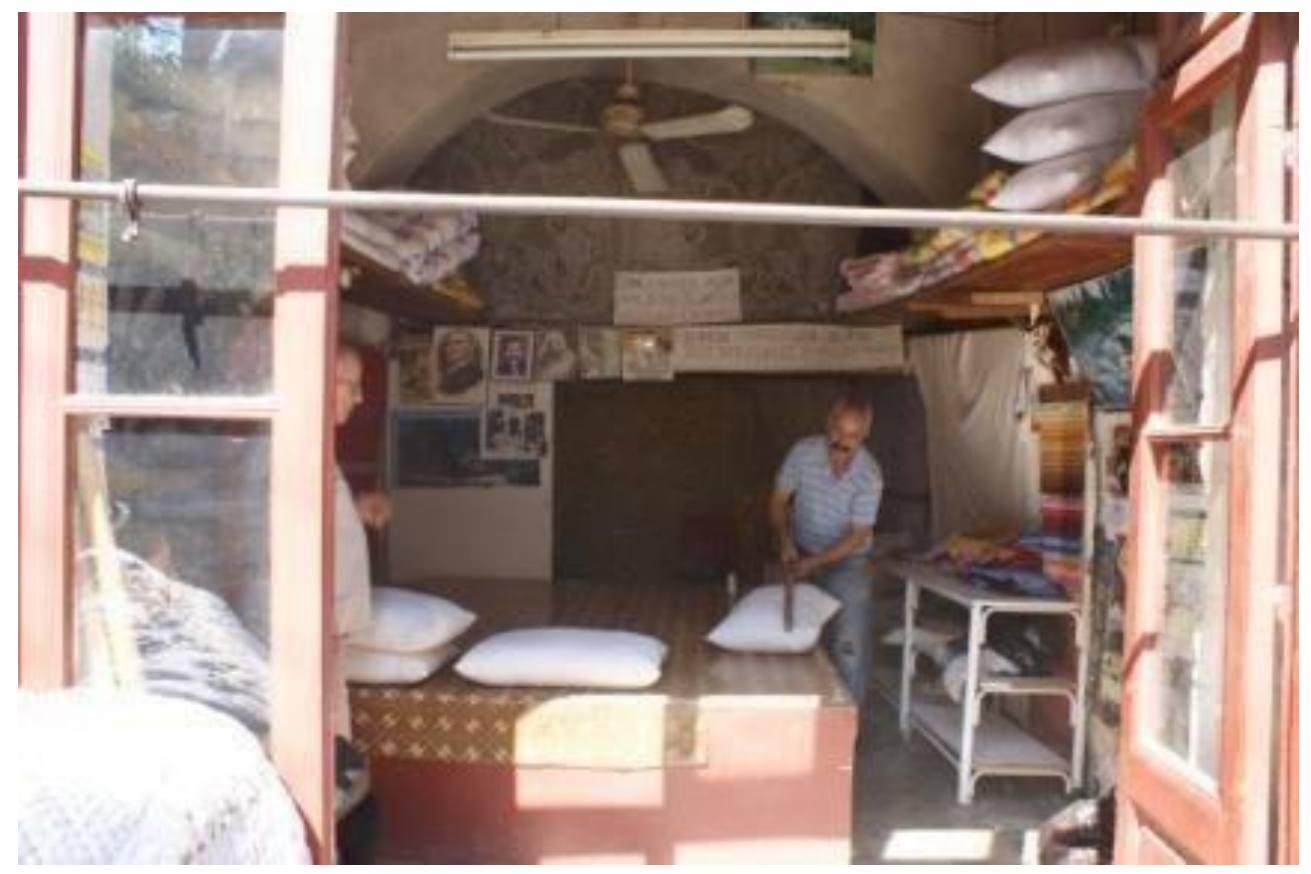

Photograph 3 Quilt Maker Workshop, Senih Çavuşoğlu 


Online Journal of Communication and Media Technologies
Volume: 8 - Issue: 2 April - 2018

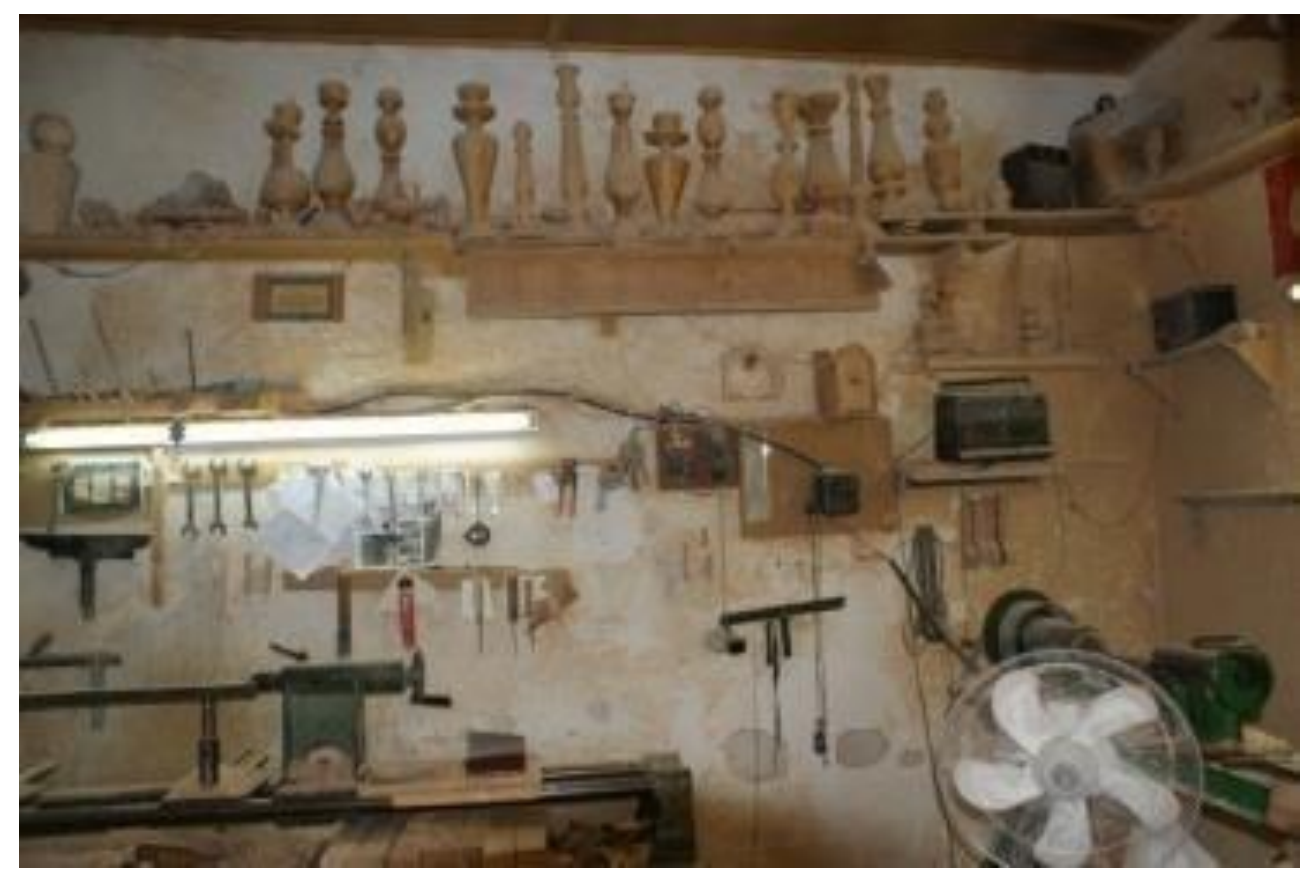

Photograph 4 Carpenter Workshop, Senih Çavuşoğlu

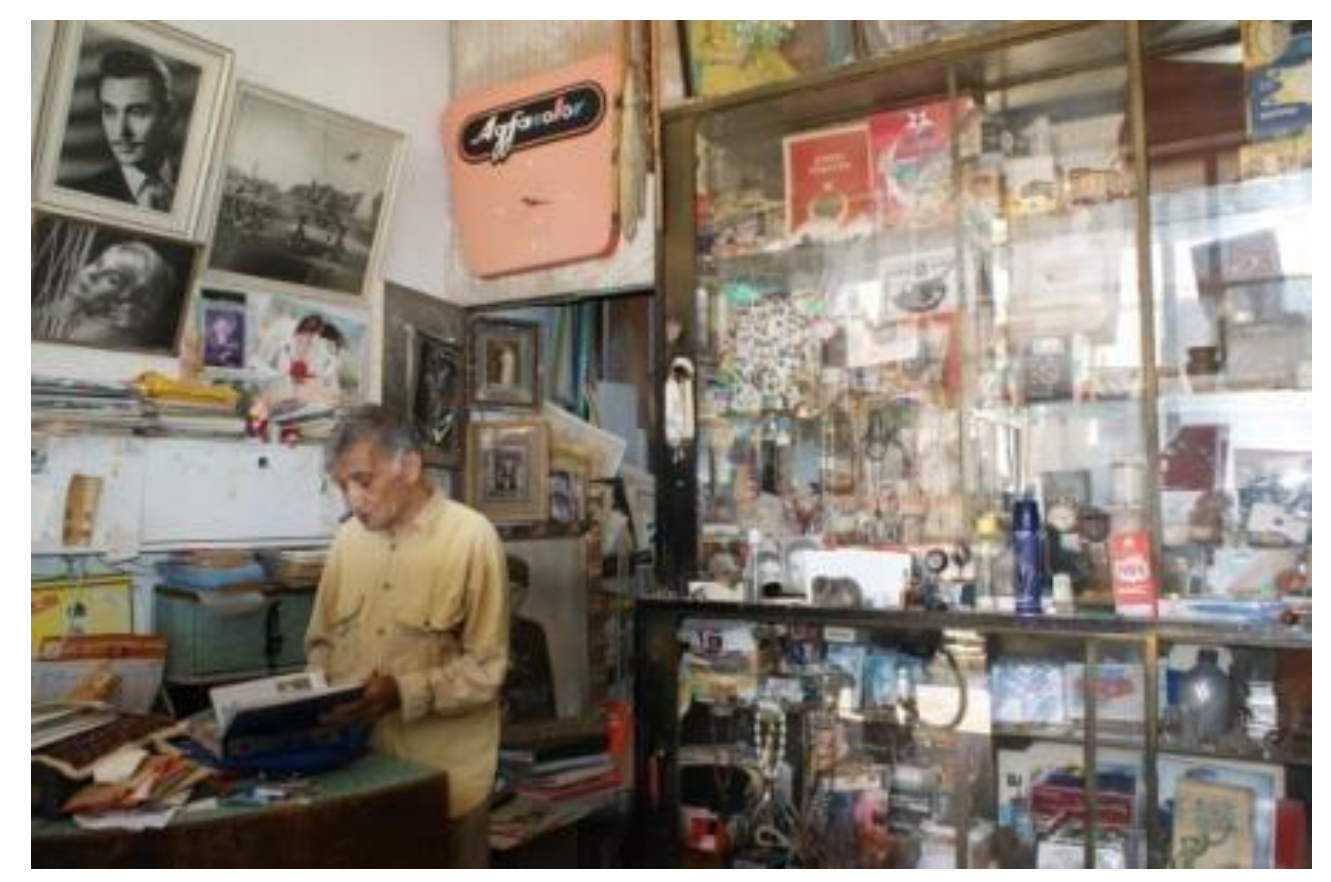

Photograph 5 Photographer's Workshop, Senih Çavuşoğlu

\section{Conclusion}

Within the flow of course of discussion about space as an identity, effects of lifestyle and culture on space, and the place and importance of workshop spaces in the Turkish Cypriot community, the workshops with aforementioned characteristics are valuable in terms of personalization of space by the inhabitant, as well as being examples of authentic spaces with the sincere space 
setup and feeling they possess as a result. Since the journey of man in time, the reckoning that he engages with time, and positioning himself over time is important for making interpretations about life; and based on the relationship of people with spaces, creating spaces for themselves, and naming themselves through their space; all the workshop spaces with features that will set an example for all these have been determined and recorded through photography. In this sense, it has been tried to draw attention to the spatial richness of workshop spaces within the context of personalization of space through the natural, sincere, spontaneous, by itself, living values that come out of the life within by emphasizing the value of these workshop spaces that reserve many clues about their inhabitants such as character, culture, lifestyle, likings, attitude, and vision. 


\section{References}

Altman, I. (1975). The environment and Social Behavior: Privacy, Personal Space, Territory, Crowding. Monterey, CA: Brooks/Cole.

Alver, K. (n.d.). Space in Story, Story in Space. Int 1 http://www.hece.com.tr/17.heceoyku.ozel2.htm

Duyan, E. (n.d.). Blind Architecture. Int 2 http://www.istanbultasarimportali.com/link.asp?cat=mimari\&id=46

Foucault, M. (1999). Archeology of Knowledge. (translator: Veli Urhan) Birey Yay1nc1lı. Güvenç, B. (1996). Humans and Culture. Remzi Kitabevi.

Kasapoğlu, E. (2004). Reflections of Mediterranean Culture on Mediterranean City. Medi3ology, International Gazimağusa Symposium, U. U. Dağlı, N. Doratlı, Ş. Ö. Hoşkara, \& P. Uluçay (Ed.), Gazimağusa, 273-279.

Kalyoncu, G. (2006). Investigation of Personalization and Space Loyalty in a Dormitory Space: İTÜ Ayş_e_Zeynep Birkan Dormitory Case (Master Thesis), İstanbul Technical University.

Proshansky, H. M., Ittelson, W. H., \& Rivlin, L. G. (1976). Freedom of Choice and Behavior in a Physical Setting, Environmental Psychology: People and Their Physical Settings, (2nd Ed.). Oxford: Holt, Rinehart \& Winston, 170-181.

Rapoport, A. (1980). Cross-Cultural Aspects of Environmental Design. In Altman, Rapoport and Wohlwill, 7-46.

Rapoport, A. (2004). Culture Architecture Design. Yap1 yayın (Yapı Endüstri Merkezi Yayınları).

Rasmussen, S. E. (1994). Lived in Architecture. Remzi Kitabevi.

Twigger-Ross, C. L., \& Uzzell, D. L. (1996). Place And Identity Processes, Journal of Environmental Psychology, 16, 205-220.

Uygur, N. (2003). Culture Theory. Yapı Kredi Yayınları.

Wells, M. M. (2000). Office clutter of meaningful personal displays; the role of office personalisation in employee and organizational well-being. Journal of Environmental Psychology, 20(3), 239-255. 